\title{
Dietary Long-Chain Polyunsaturated Fatty Acids Minimize Dexamethasone-Induced Reductions in Arachidonic Acid Status But Not Bone Mineral Content in Piglets
}

\author{
HOPE A. WEILER, AND SHIRLEY FITZPATRICK-WONG \\ Department of Foods and Nutrition, University of Manitoba, Winnipeg, Manitoba R3T 2N2, Canada
}

\begin{abstract}
The primary objective of this study was to determine whether exogenous arachidonic acid (AA) in a supplemented formula substitute for piglets or sow milk would attenuate reductions in AA status, growth, and bone mineral content (BMC) as a result of exogenous glucocorticoid excess using dexamethasone (DEX). A secondary objective was to confirm a positive effect of exogenous AA on growth and BMC of piglets fed formula and not treated with DEX as well as to determine whether the elevation in BMC was related to greater production of prostaglandin $E_{2}$ in bone. Forty-eight 5-d-old male piglets were randomized to be suckled or receive either a standard formula or the same formula, but containing AA $(0.5 \% \mathrm{wt} / \mathrm{wt}$ total fat) for $15 \mathrm{~d}$ in addition to either treatment with DEX or placebo. Piglets treated with DEX grew slower and had lower BMC of whole body, lumbar spine, and femur in addition to lower proportions of AA, but those fed standard formula had the greatest reductions. Piglets in the supplemented group weighed more than

piglets fed standard formula or suckled in both the DEX and
\end{abstract}

placebo groups. Suckled piglets had the highest BMC of whole body and femur compared with standard formula, and the supplemented group was intermediate for whole body but similar to suckled pigs for femur. Release of prostaglandin $\mathrm{E}_{2}$ was elevated only with supplementation of AA. These data indicate that supplemental AA is associated with elevated whole body and femur BMC but that BMC is not enhanced during glucocorticoid treatment. (Pediatr Res 51: 282-289, 2002)
AA, arachidonic acid
Abbreviations
BMC, bone mineral content
DEX, dexamethasone
DHA, docosahexaenoic acid
EPA, eicosapentaenoic acid
LC PUFA, long-chain polyunsaturated fatty acids
$\mathbf{P G E}_{2}$, prostaglandin $\mathrm{E}_{2}$

During growth, endogenous and exogenous glucocorticoid excess results in reduced growth and skeletal size. Reduced whole body growth and mineral accretion in the radius occurs in prematurely born infants treated with DEX, a potent glucocorticoid, as therapy for chronic lung disease $(1,2)$. Linear growth may be compromised at least to 6 mo corrected age even though DEX is usually withdrawn before estimated term date (1). Nutritional intervention during and after DEX therapy has not been widely investigated in human infants (3). Further, the response of growth and bone to DEX in premature infants fed mothers' milk compared with formula has not been established. Superior mineral bioavailability in human milk (4) may

Received August 11, 2000; accepted October 4, 2001.

Correspondence and reprint requests: Hope A. Weiler, Ph.D., Department of Foods and Nutrition, H513 Duff Roblin Building, 190 Dysart Road, University of Manitoba, Winnipeg, MB, R3T 2N2, Canada; e-mail: hweiler@ms.umanitoba.ca

Supported by The Natural Sciences and Engineering Research Council of Canada, and a New Investigator Salary Award from the Canadian Institutes of Health Research (to H.A.W.). be protective against the negative effects of DEX. In young piglets, DEX reduces intestinal calcium absorption in addition to whole body BMC and growth (5).

There are numerous other benefits associated with feeding mothers' milk such as provision of preformed LC PUFA, AA, and DHA (6) that are not present in proprietary formula in Canada and the United States. Recently in piglets, AA has been linked to greater growth and BMC compared with feeding an isocaloric formula without AA (7). These piglets were healthy and not treated with glucocorticoid. A group of suckling piglets was not included to represent the mothers' milk-fed scenario. The hypothesized mechanism for the stimulated growth and bone mass is that greater amount of precursor, AA, is available for synthesis of $\mathrm{PGE}_{2}$ in response to the calciotropic hormones during growth. $\mathrm{PGE}_{2}$ is a potent stimulator of bone formation with particular effect noted in long bones such as the tibia or femur $(8,9)$ regardless of weight-bearing stimulus $(10)$. In bone cells cultured without AA, DEX reduces production of $\mathrm{PGE}_{2}$ (11). Additionally, evidence in adult rodents treated with 
DEX suggests that AA status may be compromised by limited endogenous synthesis in liver tissue $(12,13)$. Thus far the benefit of exogenous AA to growth in healthy piglets (7), the effect of DEX on growth and bone in piglets (5), and the effect of DEX on fatty acids in adult rodents (13) have been studied separately. Thus two logical questions follow: 1) is AA status compromised by DEX treatment during growth, and 2) as mothers' milk contains AA or if AA were added to formula, would additional precursor be available for synthesis of $\mathrm{PGE}_{2}$ during DEX treatment and thereby improve bone growth and mineralization.

The piglet is an excellent model to continue investigation of the mechanisms behind glucocorticoid-induced growth failure and osteopenia. Piglets are relatively mature at birth, easily adapt to nutritional manipulation, and can be assessed for bone mass using identical technology as for preterm and term human infants. Therefore, the primary objective of the present study was to determine whether exogenous AA in supplemented formula substitute for piglets or sows' milk would attenuate reductions in AA status, growth, and BMC in piglets as a result of exogenous glucocorticoid excess using DEX. A secondary objective was to confirm a positive effect of exogenous AA on growth and $\mathrm{BMC}$ of piglets fed formula (7) and not treated with DEX, as well as to determine whether the elevation in $\mathrm{BMC}$ was related to greater production of $\mathrm{PGE}_{2}$ in bone.

\section{METHODS}

Animals and care. At $3 \mathrm{~d}$ of age, 48 male piglets were randomized to receive $15 \mathrm{~d}$ of treatment to commence at $5 \mathrm{~d}$ of age. All piglets were greater than $1300 \mathrm{~g}$ at birth and from eight litters consisting of $10-12$ piglets each with at least eight males. Treatments were diet (suckling, standard formula, or a formula containing LC PUFA) and drug (placebo or DEX). All formula-fed piglets were transported from the Glenlea Swine Research Unit, Manitoba, to the University of Manitoba on d 3 of life, and the suckling piglets remained at the Swine Research Unit in litters of 8 to 10 piglets per sow until the end of the study. Cross-fostering of other piglets to the study sows was permitted as long as the total piglets was not greater than 10 per sow. The light-to-dark cycle was $16 \mathrm{~h} / 8 \mathrm{~h}$ in both suckled and formula-fed housing facilities. To control for stress during transportation ( $20 \mathrm{~min}$ between facilities) and changes in housing, the formula-fed piglets were transported on $\mathrm{d} 3$ in a warmed container maintained at $30^{\circ} \mathrm{C}$ and capable of transporting 8 piglets $(<3 \mathrm{~kg}$ each) and then permitted a $2-\mathrm{d}$ adaptation period to the single housing, necessary to monitor feeding, before commencement of the treatments. Initially the piglets are group housed, by litter, for $4-6 \mathrm{~h}$ after transportation to observe the response to transportation and to begin feeding. The piglets maintained by the sow were housed in groups of 8 to 10 until the evening of the 15 th $d$ of study when they were transported in groups of two per container (previously used daily for attainment of body weight) followed by group housing, by litter, without the sow until necropsy.

The formula-fed piglets were taught to lap the standard liquid formula according to the method previously described (5) between d 3 and 5 of life and permitted this time to adapt to diluted formula (50\% strength initially using distilled water), then full-strength formula without symptoms of diarrhea. All procedures were in agreement with the Guide for the Care and Use of Experimental Animals (14) and approved by the University of Manitoba Protocol Management and Review Committee.

Starting on $\mathrm{d} 5$ of life, the DEX dosing regimen was $0.5 \mathrm{mg}$ $\cdot \mathrm{kg}^{-1} \cdot \mathrm{d}^{-1}$ for the first $5 \mathrm{~d}$, followed by $0.3 \mathrm{mg} \cdot \mathrm{kg}^{-1} \cdot \mathrm{d}^{-1}$, then $0.2 \mathrm{mg} \cdot \mathrm{kg}^{-1} \cdot \mathrm{d}^{-1}$ for $5 \mathrm{~d}$ each. This regimen was designed to result in a cumulative dosage of DEX that mimics that delivered to preterm infants of approximately $6 \mathrm{mg} / \mathrm{kg}(1$, $2)$. The placebo drug was an equal volume of saline $(0.9 \%$ by weight). Both treatments were delivered intramuscularly in half-dosages at $0900 \mathrm{~h}$ and $2100 \mathrm{~h}$.

The standard formula contained $60 \mathrm{~g} / \mathrm{L}$ protein, $62 \mathrm{~g} / \mathrm{L}$ carbohydrate, $62.5 \mathrm{~g} / \mathrm{L}$ fat, $2.3 \mathrm{~g} / \mathrm{L}$ calcium, and $1.8 \mathrm{~g} / \mathrm{L}$ phosphorous. The formula energy $(1005 \mathrm{kcal} / \mathrm{L})$ and linoleic acid (11.7\% of energy) were within recommended limits for healthy growing piglets between 3 and $10 \mathrm{~kg}$ as set by the National Research Council (15). The amount of dietary fat is greater than that used previously (7) in a study in which dietary fat $(37 \mathrm{~g} / \mathrm{L})$ was designed to mock the quantities in formula designed for prematurely born infants (Enfalac Premature 20 with $34 \mathrm{~g}$ fat/L and Enfalac Premature Plus with $41 \mathrm{~g}$ fat $/ \mathrm{L}$, MeadJohnson Nutritionals, Ottawa, Ontario, Canada). Thus the amount of fat in the formula used in the present study was similar to sows' milk $(62 \mathrm{~g} / \mathrm{L}$ as measured in milk $5 \mathrm{~d}$ postpartum from the Glenlea Research Unit, plus the amount of AA in sows' milk obtained at d 5 postpartum was on average $0.73 \% \mathrm{wt} / \mathrm{wt}$ and DHA was $0.08 \% \mathrm{wt} / \mathrm{wt}$ ), and contained enough linoleic acid $(13.1 \mathrm{~g} / \mathrm{L})$ to support growth. The standard formula had a total n-6:n-3 fatty acid ratio of 9.1:1.0 as a result of blending soybean, high-oleic safflower, and coconut oils, but the fatty acid-supplemented formula contained $0.5 \% \mathrm{wt} / \mathrm{wt}$ of the fat as AA (RBD-ARASCO: 40.6\% AA; Martek Biosciences Corp., Columbia, MD, U.S.A.) and $0.1 \% \mathrm{wt} / \mathrm{wt}$ DHA (RBD-DHASCO: 40.0\% DHA; Martek Biosciences Corp.). The small amount of DHA added was intended to make the formula more similar to sows' milk with respect to both AA and DHA and to ensure that the DHA status of formula-fed piglets was not reduced as a result of addition of AA to the formula. Formulas were isocaloric with equal amounts of fat and fed at $350 \mathrm{~mL} \cdot \mathrm{kg}^{-1} \cdot \mathrm{d}^{-1}$ divided into equal amounts at $0900 \mathrm{~h}, 1500 \mathrm{~h}$, and $2100 \mathrm{~h}$ for the duration of the study. Formula-fed piglets were housed individually in stainless steel cages, but group housed for 3-5 h during feeding, and ambient temperature was maintained at $29^{\circ}$ to $30^{\circ} \mathrm{C}$.

On the evening of the 15 th $\mathrm{d}$ of study, the suckling piglets were transported to the University of Manitoba and group housed under the same ambient conditions as the formula-fed piglets, with exception of the group housing. At $2100 \mathrm{~h}$, all food and water was withdrawn from all housing, resulting in 12-15 h without food before anesthesia (sodium pentobarbital $30 \mathrm{mg} / \mathrm{kg}$ ) and sample collection on the 16th $\mathrm{d}$ as collection of samples required approximately $3 \mathrm{~h}$ per block of piglets.

Growth. Weight was measured daily in the nonfed state for formula-fed piglets and at $0900 \mathrm{~h}$ in suckled piglets to the nearest gram using a scale with an animal weighing program 
(Mettler-Toledo Inc, Hightstown, NJ, U.S.A.), and average daily weight gain was calculated (grams per kilogram per day). Snout to tail length was measured to the nearest millimeter using a nonstretchable measuring tape only at the end of study while pigs were anesthetized.

Tissue samples. Blood was taken at $0900 \mathrm{~h}$ into heparinized syringes on the first day of study just before treatment using the internal jugular blind-stab technique to permit measurement of cortisol used as an index of stress induced by the study procedures. Blood was taken again at $0900 \mathrm{~h}$ on the 16th $\mathrm{d}$ of study into heparinized syringes followed by sodium pentobarbital overdose. Plasma was obtained by centrifugation at 2000 $\times g$ for 20 min at $4^{\circ} \mathrm{C}$. Plasma was centrifuged again to remove any remaining red blood cells and stored at $-80^{\circ} \mathrm{C}$ until analysis of cortisol, fatty acids, and osteocalcin. Urine was obtained using bladder puncture and stored at $-20^{\circ} \mathrm{C}$ until analysis for minerals and $N$-telopeptide.

Fatty acid analysis. Total lipids in plasma were extracted using 1:2 methanol to chloroform (vol/vol) according to the method of Folch et al. (16). Crude lipid extracts were transmethylated in $1 \mathrm{~mL}$ of $3 \mathrm{~N}$ methanolic $\mathrm{HCl}$ (Supelco Inc., Bellefonte, PA, U.S.A.) at $100^{\circ} \mathrm{C}$ for 15 min. Fatty acid methyl esters were separated by gas-liquid chromatography (Varian Star 3400, Varian Canada, Inc., Mississauga, Ontario) and using hydrogen as the carrier gas. The gas chromatograph was equipped with a $30-\mathrm{m}$-long capillary column made of fused silica and coated with DB225 (25\% cyanopropylphenyl; J\&W Scientific, Folsom, CA, U.S.A.), an 8100 autosampler, an integrator, and a flame ionization detector. Samples $(0.5 \mu \mathrm{L})$ were injected at an initial temperature of $180^{\circ} \mathrm{C}$, and the oven temperature was increased to a final temperature of $220^{\circ} \mathrm{C}$ at a rate of $3^{\circ} \mathrm{C} / \mathrm{min}$. Fatty acid methyl esters were identified by comparison with retention times of Supelco 37 component FAME mix (Supelco Inc) and expressed as percent of total lipid (\%wt/wt).

Biochemical assessment of stress and bone metabolism. Plasma cortisol was measured at baseline and necropsy using an ELISA (Cedarlane Laboratories Ltd., Hornby, Ontario, Canada). Plasma osteocalcin was analyzed by RIA (DiaSorin, Stillwater, MN, U.S.A.). Urinary $N$-telopeptide was measured in urine using ELISA (Osteomark, Ostex, Seattle, WA, U.S.A.). Plasma, urinary and femur calcium and phosphorous were wet ashed in concentrated nitric acid for $24 \mathrm{~h}$ before dilution with deionized water (5\% nitric acid) and measurement using a Varian Liberty 200 ICP emission optical spectrometer (Varian Canada, Mississauga, Ontario, Canada). $\mathrm{N}$ telopeptide, calcium, and phosphorous were corrected to creatinine as determined by the Jaffe method (procedure no. 555; Sigma Chemical Co.-Aldrich Ltd, Oakville, Ontario, Canada). Ex vivo release of $\mathrm{PGE}_{2}$ was measured in an approximately 1-g segment of tibia diaphysis incubated in Hanks' balanced salt solution for $2 \mathrm{~h}$ at $37^{\circ} \mathrm{C}$ according to the method of Dekel et al. (17). The released $\mathrm{PGE}_{2}$ was analyzed in diluted samples using an ELISA (Cedarlane Laboratories) and corrected to the weight of the tibia segment studied.

Bone mineral content. After tissues were removed, the abdominal cavity was closed with suture to maintain tissue depth. Piglet carcasses were then transported to the dual- energy x-ray absorptiometer (QDR4500W; Hologic Inc., Waltham, MA, U.S.A.). Single scans were completed to determine BMC of the whole body (software version V8.16a:5), lumbar 3 using the low-density spine program, and left femur using the subregion array hip program. All scans were performed with the piglet in the anteroposterior position with limbs extended. Whole body BMC was corrected to body length (grams per centimeter) and weight (grams per kilogram) to account for potential differences in size. Femurs were then excised and freed of soft tissue for measurement of weight and length.

Statistical analysis. The sample size required to observe a statistically significant difference in whole body BMC of $25 \pm$ $13 \mathrm{~g}$ with power of 0.80 and $\alpha$ value of 0.05 was calculated to be eight per group based on data from Weiler (7). All data are mean \pm SD unless otherwise stated. Differences observed among groups were detected using two-way ANOVA with factors being drug (placebo or DEX) and feeding (suckling, standard formula, or LC PUFA formula) with values of $p<$ 0.05 accepted as significantly different. Post hoc analysis with Student-Newman-Keuls all-pairwise test was used to identify differences among the six treatment groups. Pearson correlation coefficients were calculated to identify relationships between release of $\mathrm{PGE}_{2}$ from tibia with tibia diaphyseal calcium and phosphorous content. No other relationships were sought because other measurements of mineral metabolism (osteocalcin and $N$-telopeptide) were based on whole body bone metabolism and not just the diaphysis of tibia.

\section{RESULTS}

Piglets were similar among groups at baseline ( $5 \mathrm{~d}$ of age) for weight with a range of $2.2-2.5 \mathrm{~kg}$. Because the housing conditions necessary for inclusion of both suckled and formula-fed groups differed with respect to single versus group housing and timing of transportation to the research facility where final samples were collected, assessment of degree of stress incurred by the study conduct was necessary. Plasma cortisol values were pooled within a feeding group at baseline because treatment had not yet commenced and were similar among groups: suckled group, $151.5 \pm 76.1 \mathrm{mM}$; standard formula, $90.2 \pm 56.3 \mathrm{mM}$; and LC PUFA formula, $76.1 \pm 29.5$ $\mathrm{mM}$. By the end of study the values for piglets receiving placebo treatment continued to be similar among feeding groups: suckled, $161.7 \pm 82.2 \mathrm{mM}$; standard formula, $172.7 \pm$ $107.3 \mathrm{mM}$; and LC PUFA formula, $156.7 \pm 60.4 \mathrm{mM}$. Those piglets receiving DEX had significantly reduced values for cortisol $(p<0.01)$ compared with placebo-treated piglets, but differences among feeding groups was not evident: suckled, $28.1 \pm 21.5 \mathrm{mM}$; standard formula, $29.8 \pm 21.2 \mathrm{mM}$; and LC PUFA formula, $19.6 \pm 20.1 \mathrm{mM}$.

The average cumulative dosage of DEX was $16.7 \mathrm{mg}$ during $15 \mathrm{~d}$ or $7.1 \mathrm{mg} / \mathrm{kg}$ using weight at baseline. During the course of the $15 \mathrm{~d}$ of study, main effects of feeding as well as drug treatment were observed for growth measurements (Table 1). A main effect of feeding $(p<0.002)$ was observed with piglets that suckled gaining weight significantly slower than the two formula-fed groups and those fed standard formula gaining 
significantly slower than those fed the LC PUFA formula. A main effect of DEX treatment was significantly $(p<0.001)$ slower weight gain than placebo $(61.1 \pm 1.1$ versus $50.7 \pm$ $1.1 \mathrm{~g} \cdot \mathrm{kg}^{-1} \cdot \mathrm{d}^{-1}, n=24$ per group). After $15 \mathrm{~d}$, main effects of feeding $(p<0.001)$ and drug treatment $(p<0.001)$ were observed with all feeding groups having significantly different weights (suckling $<$ standard formula $<$ LC PUFA formula) and those treated with DEX weighing less than placebo. The same observations were made for length after $15 \mathrm{~d}$ with the only exception being similar length between the standard and LC PUFA formula-fed groups but greater than suckling piglets. Within feeding groups, all DEX-treated piglets were smaller than the placebo groups. However, those treated with DEX and fed the LC PUFA formula had similar weight gain and final weight but not length as suckling piglets treated with placebo (Table 1).

Fatty acid status as a result of the study interventions is reported as plasma linoleic acid (18:2 n-6) and its LC PUFA product AA (20:4n-6) and as linolenic acid (18:3n-3) and its LC PUFA products EPA (20:5 n-3) and DHA (22:6n-3) in Table 2. Main effects of DEX treatment $(p<0.001)$ included lower proportions of AA and DHA but greater linolenic acid in plasma than with placebo and no effect observed in linoleic acid. Main effects of feeding were as follows: piglets fed formula had greater proportions of linoleic and linolenic acids and lower EPA than suckling piglets and those fed LC PUFA had greater linolenic acid than standard formula, $p<0.001$. However, for AA, a main effect of feeding $(p<0.001)$ indicated that suckling piglets had greater proportions of the fatty acid than either formula group and those fed LC PUFA had greater AA than standard formula. No differences among feeding groups were detected for DHA.

Similar to the results of growth, a main effect of DEX treatment $(p<0.001)$ was observed for whole body, lumbar 3, and femur BMC (Fig. 1). A main effect of feeding was observed for femur BMC, in which piglets fed standard formula had significantly lower content than suckling and LC PUFA formula-fed piglets $(p<0.01)$. When whole body BMC was corrected to body weight and length, piglets that suckled had greater $(p<0.001)$ BMC per kilogram at $13.1 \mathrm{~g} / \mathrm{kg}$ than both groups fed formula and the standard formula group was greater than the LC PUFA formula group (10.6 versus $9.4 \mathrm{~g} / \mathrm{kg}$, $p<0.05$ ). A main effect of DEX was not observed for BMC per kilogram. Whole body BMC per length was significantly elevated $(p<0.01)$ in the suckled group at $1.3 \mathrm{~g} / \mathrm{cm}$ compared with both formula groups at $1.1 \mathrm{~g} / \mathrm{cm}$ each. A main effect of DEX was observed to reduce BMC per length (1.2 versus 1.1 $\mathrm{g} / \mathrm{cm}, p<0.05)$.

Plasma osteocalcin was similar in suckling and LC PUFA piglets but lower than the group fed standard formula, yet $N$-telopeptide in the LC PUFA group was higher than in the suckling group (Table 3 ). A main effect of DEX treatment $(p<$ $0.01)$ to reduce $N$-telopeptide was observed. Release of $\mathrm{PGE}_{2}$ from tibia was similar between suckling and standard formula groups, but the LC PUFA group had higher quantities released ex vivo, with those receiving DEX having the highest values. The amount of calcium and phosphorous in the same section of tibia was also highest in the LC PUFA DEX group. Main effects of feeding $(p<0.001)$ and DEX treatment $(p<0.001)$ were also observed for tibia calcium and phosphorous (Table 3). Release of $\mathrm{PGE}_{2}$ was significantly correlated with the amount of calcium $(r=0.41, p=0.008, n=48)$ and phosphorous $(r=0.50, p=0.001, n=48)$ per gram of bone segment. The weight and length of the femur were greater in placebo groups than DEX groups (main effects, $p<0.001$ ) with similar values for weight and length in the formula groups that were greater than for the suckling group (Table 3). No differences among groups were observed for plasma total calcium or phosphorous or urinary calcium or phosphorous after correction to creatinine (data not shown). However, a main effect of feeding on urinary phosphorous corrected to creatinine was observed, in which values for suckled piglets $(3.25 \pm 1.63 \mathrm{mM} / \mathrm{mM})$ were significantly $(p=0.005)$ greater than piglets fed standard formula $(1.10 \pm 1.99 \mathrm{mM} / \mathrm{mM})$ or LC PUFA formula $(1.94 \pm 1.63 \mathrm{mM} / \mathrm{mM})$.

Table 1. Weight, weight gain, and length in piglets that were suckled or fed either a standard or LC PUFA formula and either placebo or DEX treatment for $15 d$

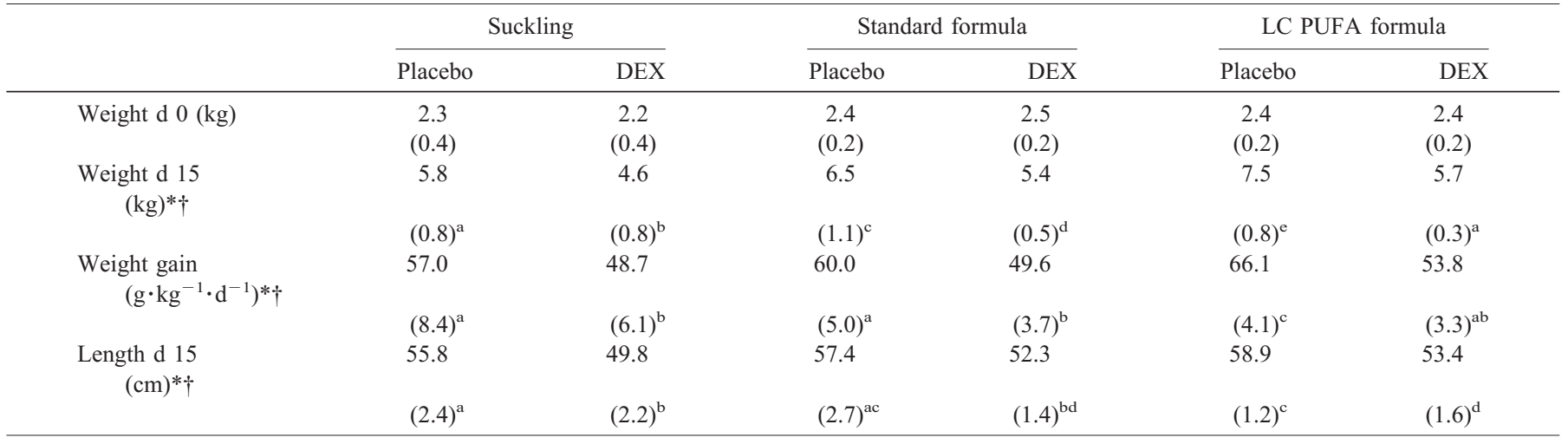

Values are mean (SD), $n=8$ per group.

$* p<0.05$, effect of treatment in which DEX caused lower values.

$\dagger p<0.05$, effect of feeding in which the LC PUFA formula $>$ standard formula $>$ suckling for weight, all formula $>$ sow for length, and LC PUFA formula $>$ standard formula or suckled for weight gain.

In rows, values with different superscripts are significantly different, $p<0.05$. 
Table 2. Plasma fatty acids in piglets that were suckled or fed either a standard or LC PUFA formula and either placebo or DEX treatment for $15 d$

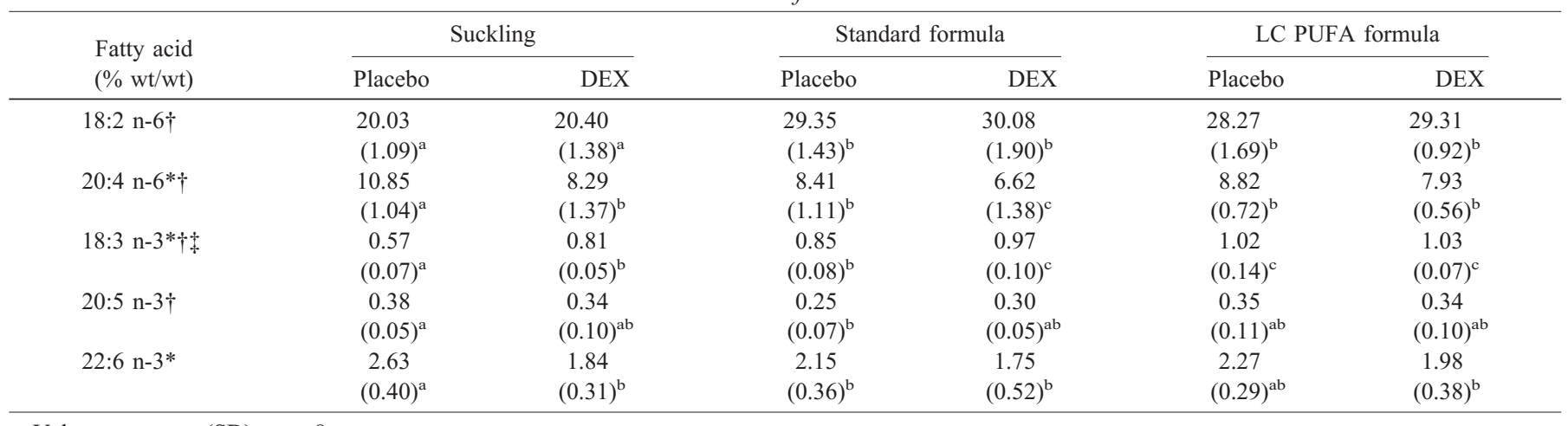

Values are mean (SD), $n=8$ per group.

$* p<0.05$ effect of treatment for which values in the DEX groups are lower.

$\dagger p<0.05$ effect of feeding for which 18:2 n-6 and 18:3 n-3 suckled group $<$ other groups; 20:4 n-6 suckled group $>$ LC PUFA formula group $>$ standard formula group; and 20:5 n-3 standard formula greater $>$ suckled or LC PUFA formula groups.

$\ddagger p<0.05$ interaction effect (treatment $\times$ feeding).

In rows, values with different superscripts are significantly different, $p<0.05$.

\section{DISCUSSION}

In agreement with previous observations in young piglets (18), growth and BMC were reduced in this study by a tapering regimen of DEX treatment that was intended to approximate the cumulative dosage in human preterm infants $(1,2)$ and during a period of what is normally expected to be very rapid growth in both humans and pigs. In preterm infants (19), piglets $(5,18)$, rabbits $(20)$, and mice $(21)$, growth and BMC of long bones is reduced by DEX in a wide range of dosages. The new information, with respect to growth and bone, gained through the present investigation is that piglets fed a formula substitute with LC PUFA display less severe reductions in growth, but not BMC, owing to DEX than is observed with standard formula.

Fatty acids were measured in plasma as opposed to liver because plasma circulates to bone where it may affect bone cell activity and $\mathrm{PGE}_{2}$ synthesis. After only $15 \mathrm{~d}$, DEX reduced plasma AA and DHA in the suckling piglets and AA in the piglets fed standard formula. Addition of LC PUFA to formula prevented the reductions in AA caused by DEX. Values, however, were below those reported for suckling piglets treated with placebo, but this was as a consequence of formula feeding not DEX treatment. The DEX-related reductions were not likely linked to lack of precursor as each treated group had equal or greater proportions of linoleic and linolenic acids compared with the matched feeding placebo group. Thus the reductions in LC PUFA must have been linked to synthesis or increased use during growth. The former is most likely as injection of DEX (13) or addition to drinking water (12) causes significant reductions in liver $\Delta 5$ - and $\Delta 6$-desaturase enzymes responsible for increasing the number of double bonds in 22and 24-carbon fatty acids.

The mechanisms by which DEX reduces growth and alters bone metabolism were postulated to be related to low AA status and therefore in bone lower precursor for (12) and synthesis of (11) $\mathrm{PGE}_{2}$. Thus the elevation in $\mathrm{PGE}_{2}$ in the DEX-LC PUFA group was unexpected and correlated with greater mineral density (grams of mineral per gram of bone).
However, a benefit to whole body $\mathrm{BMC}$ is only evident in the placebo piglets. The cause of this seems more related to a positive effect on body weight (weight-bearing mass) rather than a larger skeleton as correction of whole body BMC to weight suggested less mineral per kilogram in the LC PUFA group compared with other groups. When corrected to length the amount of mineral was similar between formula-fed groups. Therefore, exogenous LC PUFA appears most beneficial to weight gain and thereby BMC when exogenous glucocorticoid is not a factor. The higher mineral (calcium and phosphorous) content in tibia diaphysis in DEX-treated piglets was unexpected based on previous studies in which BMC of femur was lower because of $\operatorname{DEX}(5,18)$. The higher mineral content may actually reflect reduced growth and collagen deposition as supported by suppressed long bone growth in young rabbits treated with DEX (20) and reduced protein content (collagen) of long bones in young mice treated with DEX (21).

Without DEX treatment, piglets fed the LC PUFA formula had a higher rate of weight gain and final weight, but not length, than both suckling and standard formula-fed piglets. In contrast, suckling piglets had significantly greater whole body and femur BMC than piglets fed standard formula, with those fed LC PUFA having intermediate values. Thus our results suggest that piglets, like human infants $(4,22,23)$, may grow slower when nourished with maternal milk than with milk substitute. Additionally, a positive affect of LC PUFA on weight growth and BMC was confirmed after $15 \mathrm{~d}$ of feeding using the same ratio of AA to DHA as previously reported in older piglets studied for $14 \mathrm{~d}$ (7). The amount of total fat (62.5 $\mathrm{g} / \mathrm{L}$ ) used in the formula in this study was greater than previously used $(37 \mathrm{~g} / \mathrm{L})$, suggesting that the ratio of AA to DHA rather than the amount of these LC PUFA is responsible for the elevated growth rate and BMC. However, the difference in amount of fat could have been responsible for the smaller elevation seen in AA measured in plasma $(0.4 \% \mathrm{wt} / \mathrm{wt}) \mathrm{com}-$ pared with the previous study $(3.4 \% \mathrm{wt} / \mathrm{wt})$. 

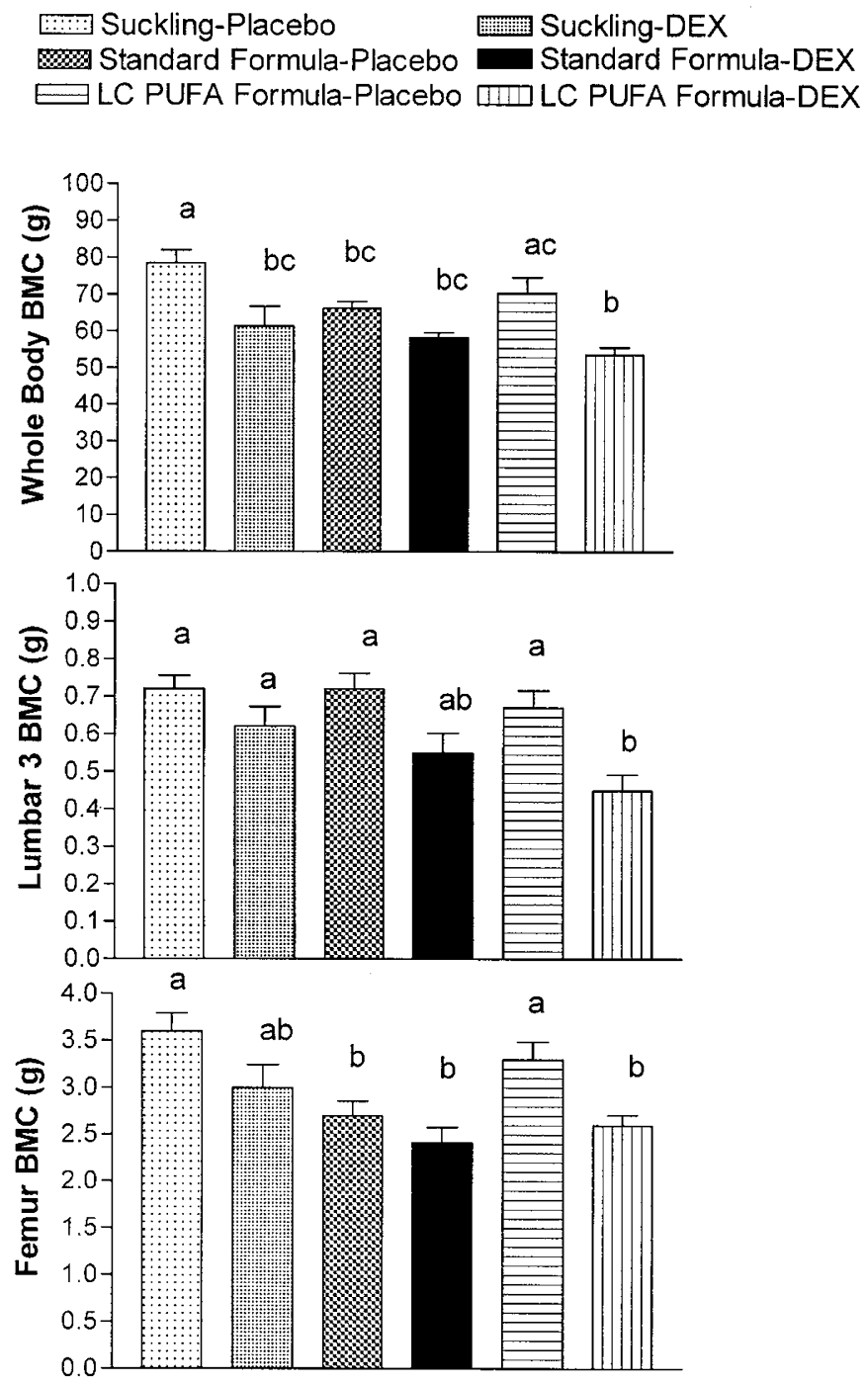

Figure 1. BMC of whole body, lumbar 3, and femur in piglets treated with or without DEX for $15 \mathrm{~d}$ and either suckling or fed standard formula or one supplemented with LC PUFA ( $n=8$ per group). A main effect of DEX was observed for each measurement $(p<0.01)$. A main effect of diet was observed for whole body $(p<0.05)$ and femur BMC $(p<0.001)$, in which suckled piglets had greater BMC than formula-fed piglets. Significant differences among the six groups are indicated by different letters for each measurement.

The stimulatory effect of LC PUFA on growth in piglets (7) contradicts reports of no effect of LC PUFA supplementation on growth in human infants (24). The total n-6 to n-3 fatty acid ratio used in this study $(9: 1)$ is similar to standard infant formula, but the AA to DHA ratio of 5:1 is very different from that used in preterm infant formula at $1.4: 1(0.50 \% \mathrm{AA}$ and $0.35 \%$ DHA) (24) using the same LC PUFA source as for the piglet formula. Thus, improved growth with feeding LC PUFA formula to piglets cannot be extrapolated to human preterm infants despite similar growth patterns when nourished by maternal or substitute milk.

In contrast to the results of growth, suckling piglets have elevated BMC of whole body and femur, but not of lumbar spine. A mechanism to explain these differences would thus likely exist in the long bones. Femurs of suckling piglets weighed less and were shorter in comparison to the standard formula-fed piglets but BMC was higher; suggesting that both linear and appositional growth are slower with suckling. The lower osteoblast (osteocalcin) and osteoclast ( $N$-telopeptide) activity in the suckling group support this explanation. In contrast, the higher osteocalcin and $N$-telopeptide in the standard group suggests higher osteoblast and osteoclast cell activities or elevated bone turnover and modeling. The similar values of $\mathrm{PGE}_{2}$ in the suckling and standard formula-fed groups rule out $\mathrm{PGE}_{2}$ as a single causative agent in modulating femur bone metabolism and size and BMC in the suckling and standard formula-fed piglets. The difference in BMC may be related to mineral bioavailability (4). The clear elevation of $\mathrm{PGE}_{2}$ and femur BMC and the reduced osteocalcin in the LC PUFA formula group in relation to the standard formula group can only be attributed to addition of LC PUFA as the formulas were otherwise identical. The higher rate of whole body growth was accompanied by an intermediate amount of osteoclast activity as indicated by $N$-telopeptide that we speculate is caused primarily by rapid growth and thus bone modeling rather than resorption. From studies in rodents treated with $\mathrm{PGE}_{2}$ injections alone in which mineralization is elevated despite limb disuse $(10,25)$, ovariectomy (26), or orchidectomy (8), it is possible that endogenous $\mathrm{PGE}_{2}$ partially caused the observation of elevated BMC in our piglets. Alteration in LC PUFA status has not demonstrated deleterious effects in the short-term on linear bone growth or BMC in piglets (7) or chicks $(27,28)$. Recently, growing rabbits fed fish oil for $40 \mathrm{~d}$ are reported to have shorter bones than expected for age (29). In both the rabbits and chicks, new bone formation rate is reduced by fish oil, suggesting that excess n-3 fatty acids impairs bone growth. In the present and previous report in pigs (7), in which small amounts of both n-3 and n-6 LC PUFA were fed together, BMC was elevated and linear growth unaffected. The fact that plasma DHA was not elevated in the LC PUFA group, but AA and EPA were, suggests that the latter two are linked to higher BMC because both are prostaglandin precursors.

It is too early to postulate existence of similar observations in growth and bone between piglets and human infants. The piglet is known to have a greater capacity to synthesize fatty acids than human infants (30) and has different dietary requirements (15). Further, this research is limited by the potential for type 2 errors inasmuch as the post hoc analyses were not corrected for multiplicity and by the potential for different housing conditions between the suckled and formula-fed piglets to have affected the results. On the basis of plasma cortisol, stress incurred during housing and transportation was similar among feeding groups. Although cortisol itself may not reflect all aspects of stress, it is commonly used to assess stress during transportation of pigs and known to decline to expected concentrations within $6 \mathrm{~h}$ after transportation and to resume expected circadian rhythm $(31,32)$, less than the period between transportation and sampling used in this study. Further, an estimate of the amount of sows' milk consumed was not feasible in this study to allow comparison of milk volume consumed among feeding groups. A last point of caution is the high degree of variability in osteocalcin and $\mathrm{N}$-telopeptide 
Table 3. Biochemical assessment of bone mineral metabolism in plasma, urine, and bone from piglets that were suckled or fed either a standard or LC PUFA formula and either placebo or DEX treatment for $15 d$

\begin{tabular}{|c|c|c|c|c|c|c|}
\hline & \multicolumn{2}{|c|}{ Suckling } & \multicolumn{2}{|c|}{ Standard formula } & \multicolumn{2}{|c|}{ LC PUFA formula } \\
\hline & Placebo & DEX & Placebo & DEX & Placebo & DEX \\
\hline \multicolumn{7}{|l|}{ Plasma } \\
\hline \multicolumn{7}{|l|}{ Urine } \\
\hline$N$-telopeptide:creatinine $(\mu \mathrm{M} / \mathrm{mM})^{* \dagger}$ & $\begin{array}{c}4.80 \\
(1.26)^{\mathrm{a}}\end{array}$ & $\begin{array}{l}3.48 \\
(2.15)^{\mathrm{a}}\end{array}$ & $\begin{array}{c}8.84 \\
(3.24)^{\mathrm{b}}\end{array}$ & $\begin{array}{c}3.94 \\
(0.64)^{\mathrm{a}}\end{array}$ & $\begin{array}{l}7.87 \\
(2.95)^{\mathrm{b}}\end{array}$ & $\begin{array}{c}5.35 \\
(0.90)^{\mathrm{a}}\end{array}$ \\
\hline $\mathrm{PGE}_{2}$ (ng/g tibia diaphysis) $)^{\dagger}$ & $\begin{array}{c}8.6 \\
(3.5)^{\mathrm{a}}\end{array}$ & $\begin{array}{c}9.5 \\
(3.2)^{\mathrm{a}}\end{array}$ & $\begin{array}{l}10.4 \\
(2.8)^{\mathrm{a}}\end{array}$ & $\begin{array}{l}11.6 \\
(2.3)^{\mathrm{a}}\end{array}$ & $\begin{array}{l}20.0 \\
(7.4)^{\mathrm{b}}\end{array}$ & $\begin{array}{c}27.0 \\
(12.4)^{\mathrm{c}}\end{array}$ \\
\hline Calcium (mg/g tibia diaphysis) ${ }^{* \dagger}$ & $\begin{array}{l}161.8 \\
(17.1)^{\mathrm{a}}\end{array}$ & $\begin{array}{l}174.5 \\
(28.3)^{\mathrm{a}}\end{array}$ & $\begin{array}{l}142.8 \\
(20.5)^{\mathrm{a}}\end{array}$ & $\begin{array}{l}151.3 \\
(24.4)^{\mathrm{a}}\end{array}$ & $\begin{array}{l}174.7 \\
(45.1)^{\mathrm{a}}\end{array}$ & $\begin{array}{l}223.6 \\
(35.7)^{\mathrm{b}}\end{array}$ \\
\hline Phosphorous (mg/g tibia diaphysis) ${ }^{*} \dagger$ & $\begin{array}{l}82.4 \\
(8.3)^{\mathrm{a}}\end{array}$ & $\begin{array}{c}88.4 \\
(12.4)^{\mathrm{a}}\end{array}$ & $\begin{array}{l}72.2 \\
(8.4)^{\mathrm{a}}\end{array}$ & $\begin{array}{c}77.8 \\
(11.5)^{\mathrm{a}}\end{array}$ & $\begin{array}{c}90.7 \\
(23.2)^{\mathrm{a}}\end{array}$ & $\begin{array}{l}115.7 \\
(16.8)^{b}\end{array}$ \\
\hline Femur weight $(\mathrm{g})^{* \dagger} \dagger$ & $\begin{array}{l}26.0 \\
(3.9)^{\mathrm{a}}\end{array}$ & $\begin{array}{l}18.9 \\
(2.9)^{\mathrm{b}}\end{array}$ & $\begin{array}{l}29.2 \\
(3.4)^{\mathrm{c}}\end{array}$ & $\begin{array}{l}21.6 \\
(1.9)^{\mathrm{b}}\end{array}$ & $\begin{array}{l}29.4 \\
(3.3)^{\mathrm{c}}\end{array}$ & $\begin{array}{l}22.3 \\
(1.4)^{\mathrm{abd}}\end{array}$ \\
\hline
\end{tabular}

Values are mean (SD), $n=8$ per group.

$* p<0.05$ effect of treatment for which DEX results in lower values for all but calcium and phosphorous.

$\dagger p<0.05$ effect of feeding: osteocalcin standard formula $>$ other groups; $N$-telopeptide suckled $<$ other groups; PGE $_{2}$ LC PUFA formula $>$ other groups; calcium and phosphorous LC PUFA formula $>$ suckled $>$ standard formula; and femur weight and length suckled $<$ other groups.

In rows, values with different superscripts are significantly different, $p<0.05$.

observed in this study compared with others in piglets of similar age but fed less dietary fat $(7,18)$. The higher variability could have caused type 1 errors inasmuch as the sample size was based on whole body BMC and not biochemistry.

In summary, DEX treatment reduces LC PUFA status as indicated by plasma values in addition to growth and $\mathrm{BMC}$ regardless of feeding. Addition of LC PUFA to formula was confirmed to stimulate growth and BMC and linked to elevated $\mathrm{PGE}_{2}$ release from bone. Addition of LC PUFA did not attenuate the DEX-induced reductions in growth or whole body BMC despite improved AA status and greater $\mathrm{PGE}_{2}$ in bone. Whether addition of LC PUFA to infant formula poses an advantage or disadvantage to growth and bone in healthy preterm infants or during DEX treatment has yet to be reported.

Acknowledgments. The authors thank Marilyn Latta for her technical assistance and the staff at the Glenlea Research Station for routine care and treatment of the suckling piglets. The formula was provided in kind by Ross Abbott Laboratories, Columbus, OH, U.S.A.

\section{REFERENCES}

1. Weiler HA, Paes B, Shah JK, Atkinson SA 1997 Longitudinal assessment of growth and bone mineral accretion in prematurely born infants treated for chronic lung disease with dexamethasone. J Early Hum Dev 47:271-286

2. Ward W, Atkinson S, Donovan S, Paes B 1999 Bone metabolism and circulating IGF-1 and IGFBPs in dexamethasone-treated preterm infants. J Early Hum Dev 56:127-141

3. Brunton JA, Saigal S, Atkinson SA 1998 Growth and body composition in infants with bronchopulmonary dysplasia up to 3 months corrected age: a randomized trial of a high-energy nutrient-enriched formula fed after hospital discharge. J Pediatr $133: 340-345$

4. Schanler RJ, Shulman RJ, Lau C 1999 Feeding strategies for premature infants: beneficial outcomes of feeding fortified human milk versus preterm formula. Pediatrics $103: 1150-1157$
5. Weiler H, Wang Z, Atkinson S 1995 Dexamethasone treatment impairs calcium regulation and reduces bone mineralization in infant pigs. Am J Clin Nutr 61:805811

6. Nutrition Committee, Canadian Paediatric Society 1995 Nutrient needs and feeding of premature infants. Can Med Assoc J 152:1765-1785

7. Weiler H 2000 Dietary supplementation of arachidonic acid is associated with higher whole body weight and bone mineral density in growing pigs. Pediatr Res 47:692697

8. Li M, Jee W, Ke H, Tang L, Ma Y, Liang X, Setterberg R 1995 Prostaglandin E administration prevents bone loss induced by orchidectomy in rats. J Bone Miner Res 10:66-73

9. Tang L, Cullen D, Yee J, Jee W, Kimmel D 1997 Prostaglandin $E_{2}$ increases the skeletal response to mechanical loading. J Bone Miner Res 12:276-282

10. Akamine T, Jee W, Ke H, Li X, Lin B 1992 Prostaglandin $E_{2}$ prevents bone loss and adds extra bone to immobilized distal femoral metaphysis in female rats. Bone 13:11-22

11. Hughes-Fulford M, Appel R, Kumegawa M, Schmidt J 1992 Effect of dexamethasone on proliferating osteoblasts: inhibition of prostaglandin $\mathrm{E}_{2}$ synthesis, DNA synthesis, and alterations in actin cytoskeleton. Exp Cell Res 203:150-156

12. Brenner R 1990 Endocrine control of fatty acid desaturation. Biochem Soc Trans 18:773-775

13. de Gomez Dumm I, de Alaniz M, Brenner R 1979 Effect of glucocorticoids on the oxidative desaturation of fatty acids by rat liver microsomes. J Lipid Res 20:834-839

14. Canadian Council on Animal Care 1993 Guide to the Care and Use of Experimental Animals, 2nd Ed, Vol 1. Bradda Printing Services Inc., Ottawa, Canada, pp 34-37, 51-56, 188

15. National Research Council 1998 Nutrient Requirements of Swine, 10th Ed. National Academy Press, Washington, DC, pp 9-115

16. Folch J, Lees M, Stanley G 1957 A simple method for total lipid-extraction and purification. J Biol Chem 226:497-509

17. Dekel S, Lenthall G, Francis MJ 1981 Release of prostaglandins from bone and muscle after tibial fracture. An experimental study in rabbits. J Bone Joint Surg [Br] 63-B: $185-189$

18. Ward WE, Donovan SM, Atkinson SA 1998 Dexamethasone-induced abnormalities in growth and bone metabolism in piglets are partially attenuated by growth hormone with no synergistic effect of insulin-like growth factor-I. Pediatr Res 44:215-221

19. Gibson AT, Pearse RG, Wales JKH 1993 Growth retardation after dexamethasone administration: assessment by knemometry. Arch Dis Child 69:505-509

20. Baron J, Huang Z, Oerter KE, Bacher JD, Cutler Jr GB 1992 Dexamethasone acts locally to inhibit longitudinal bone growth in rabbits. Am J Physiol 263:E489-E492

21. Altman A, Hochberg Z, Silbermann M 1992 Interactions between growth hormone and dexamethasone in skeletal growth and bone structure of the young mouse. Calcif Tissue Int 51:298-304

22. Nielsen GA, Thomsen BL, Michaelsen KF 1998 Influence of breastfeeding and complementary food on growth between 5 and 10 months. Acta Paediatr 87:911-917 
23. Dewey K, Heinig M, Nommsen L, Peerson J, Lonnerdal B 1993 Breast-fed infants are leaner than formula-fed infants at $1 \mathrm{y}$ of age: the DARLING study. Am J Clin Nutr 57:140-145

24. Vanderhoof J, Gross S, Hegyi T, Clandinin T, Porcelli P, DeCristofaro J, Rhodes T, Tsang R, Shattuck K, Cowett R, Adamkin D, McCarton C, Heird W, Hook-Morris B, Pereira G, Chan G, Van Aerde J, Boyle F, Pramuk K, Euler A, Lien E 1999 Evaluation of a long-chain polyunsaturated fatty acid supplemented formula on growth, tolerance and plasma lipids in preterm infants up to 48 weeks postconceptional age. J Pediatr Gastroenterol Nutr 29:318-326

25. Jee W, Ke H, Li X, Tang L, Zeng Q 1992 Prostaglandin $\mathrm{E}_{2}$ prevents disuse-induced cortical bone loss. Bone 13:153-159

26. Ma Y, Li X, Jee S, McOsker J, Liang X, Setterberg R, Chow S 1995 Effects of prostaglandin $E_{2}$ and $F_{2}$ on the skeleton of osteopenic ovariectomized rats. Bone 17:549-554

27. Watkins B, Shen C, Allen K, Seifert M 1996 Dietary (n-3) and (n-6) polyunsaturates and acetylsalicylic acid alter ex vivo $\mathrm{PGE}_{2}$ biosynthesis, tissue IGF-1 levels, and bone morphometry in chicks. J Bone Miner Res 11:1321-1332
28. Watkins B, Shen C, McMurtry J, Xu H, Bain S, Allen K, Seifert M 1997 Dietary lipids modulate bone prostaglandin $\mathrm{E}_{2}$ production, insulin-like growth factor-1 concentration and formation rate in chicks. J Nutr 127:1084-1091

29. Judex S, Wohl G, Wolff R, Leng W, Gillis A, Zernicke R 2000 Dietary fish oil supplementation adversely affects cortical bone morphology and biomechanics in growing rabbits. Calcif Tissue Int 66:443-448

30. Moris S, Simmer K, Van Barneveld R, Gibson R 1999 Developmental sensitivity of the piglet brain to docosahexanoic acid. Pediatr Res 46:401-405

31. Brown SN, Knowles TG, Edwards JE, Warriss PD 1999 Behavioural and physiological responses of pigs to being transported for up to 24 hours followed by six hours recovery in lairage. Vet Rec 145:421-426

32. Dalin AM, Magnusson U, Haggendal J, Nyberg L 1993 The effect of transport stress on plasma levels of catecholamines, cortisol, corticosteroid-binding globulin, blood cell count, and lymphocyte proliferation in pigs. Acta Vet Scand $34: 59-68$ 